\title{
Abstracts of Papers Presented at the 39th Annual Meeting of the Association for Applied Psychophysiology and Biofeedback
}

\author{
Fredric Shaffer
}

Published online: 28 November 2008

(C) Springer Science+Business Media, LLC 2008

\section{Erratum to: Appl Psychophysiol Biofeedback DOI 10.1007/s10484-008-9061-2}

The following is the correct text for the abstract, "A Reevaluation of the Web Dorsum for Monitoring Hand Temperature".

\section{A Reevaluation of the Web Dorsum for Monitoring Hand Temperature}

Adam Kabins and Joseph Goedde, Fred Shaffer, PhD (Faculty Mentor)

The present within-subjects study compared the web dorsum temperature monitoring site to five other sites on each hand during baseline and serial-sevens stressor conditions. Thirty-nine undergraduates (20 men and 19 women, 3 lefthanded and 36 right-handed), ages 18-23, volunteered for academic credit. Researchers randomly assigned participants to 1 of 5 sequences of monitoring six sites (the first phalanx of each finger and the web dorsum of each hand) using a single Raytek Raynger ST infrared thermometer. Participants were stabilized for $15 \mathrm{~min}$ in a $77^{\circ} \mathrm{F}$ room and were then monitored sitting upright with eyes open during 2-min baseline and serial-sevens conditions. Researchers sequentially monitored six sites on one hand and then six sites on the other hand for $30 \mathrm{~s}$. The starting hand was randomized across subjects. After each condition, participants rated their level of subjective stress on a 7-point Likert scale. For the left hand, a GLM Repeated Measures analysis found that there were no significant temperature differences between the web dorsum and the other five sites during baseline (Figs. 1, 2). During the serial-sevens stressor, there was a significant difference among the six temperature sites, $F(5,190)=3.52, p=.005$. A priori tests revealed that the web dorsum was $1-1.5^{\circ} \mathrm{F}$ warmer than every site but the thumb. For the right hand, there was a significant difference among the six temperature sites during baseline, $F(5,190)=4.60, p=.001$, and the serialsevens stressor, $F(5,190)=3.71, p=.003$. A priori tests revealed that the web dorsum was $1-2.1^{\circ} \mathrm{F}$ warmer than every site but the thumb and second finger during both the baseline condition and the serial-sevens stressor. These findings revealed that the relationship between temperatures at the web dorsum and five other sites depended on both the hand and experimental condition. The web dorsum was warmer than the majority of the other sites on the left hand during the serial-sevens stressor and on the right hand during both baseline and serial-sevens stressor conditions.

The online version of the original article can be found under doi: 10.1007/s10484-008-9061-2.

F. Shaffer $(\bowtie)$

Psychology Department, Truman State University,

100 E. Normal, Kirksville, MO 63501, USA

e-mail: fredricshaffer@gmail.com 
